\title{
Investigation of the Hygrothermal Effect on the Nanocomposite Material under High Strain Rate Torsion
}

\author{
Fadhel Abbas Abdullah", Zahra khalid Hamdan \\ College of Engineering, Al-Mustansiriayah University, Baghdad, Iraq
}

Copyright $\subset 2018$ by authors, all rights reserved. Authors agree that this article remains permanently open access under the terms of the Creative Commons Attribution License 4.0 International License

\begin{abstract}
This study aims to explain the effect of high strain rate torsion on unidirectional fiber glass / epoxy composite with and without adding nano particles (carbon and alumina) with weight percentage $2 \%$ and study the effect of the temperature and humidity on the samples under torsion dynamic test. Using the torsional Hopkinson split bar to testing under angle of the twist $\theta=10^{\circ}$. It can noticed that the maximum of the shear (stress, strain) of the composite increased with adding nano particles by rate of $(24.8 \%, 3.2 \%)$ with added $2 \%$ nano carbon and $(26 \%, 8.5 \%)$ with added $2 \%$ nano alumina, where the shear stress, shear strain and shear strain rate of all samples decreased with increasing (temperature and humidity) with different percentages. Finally, it was modifying Johnson-Cook constitutive model by adding parameter represented the humidity effect to simulate the experimental results, and then it was found the error percentages between the experimental results and theoretical results which range $(0.0044 \%$ and $15.5 \%)$.
\end{abstract}

Keywords Nanocomposite, Hopkinson, Hygrothermal Effect, High Strain Rate Torsion

\section{Introduction}

In a lot of engineering applications the materials loaded at strain rate from quasi-static loading which ranges $10^{-5} \mathrm{~s}^{-1}$ to dynamic loading at strain rate $10^{3} \mathrm{~s}^{-1}$ while the hydraulic machines which used normally to testing material at strain rates up to $5 \mathrm{~s}^{-1}$ [1]. The split Hopkinson pressure bar (SHPB) device is using to make high strain rate that involve strain rate range $\left(10^{2}\right.$ to $\left.10^{4}\right) \mathrm{s}^{-1}$ for testing material. Materials pass in high strain rates deformation in different applications, e.g. engineering applications such as bullet proof armor, has crashed worthiness of vehicles, impact resistant pressure vessel and events such as penetrations, explosions and penetrations. In addition to forming processes as rolling, extrusion, and high speed machining can also lead in high strain rate deformation $[2,3]$ for have the better design and safety analysis of element is required testing the material at high strain rate NASA John H. Glenn (2003)[4] studied the effect of strain rate on mechanical response of three types of epoxy resins. The experimental results progress the information needed for NASA scientists to development which can hgfgh98`1 then it be used in the design. using a torsional split Hopkinson bar to testing three types of epoxy resins (PR-520, E-862 and 977-2 ) under shear stress at different strain rates with ranges $\left(5 \times 10^{-5}\right.$ to 2 and 400 to 1000$) s^{-1}$ and the temperature testing used at room temperature and $80^{\circ} \mathrm{C}$. The results shown that all the strain rate used and temperatures significantly effect on the response of epoxy and the maximum shear stress decrease when the temperature increased and increased with increased strain rate for all resins, for example the shear stress increased from $48 \mathrm{Mpa}$ to $85 \mathrm{Mpa}$ when the strain rate increased from $1.3 \times 10^{-4} s^{-1}$ to $700 s^{-1}$ for E-862. M. Nabil Bassim (2012) [5] used torsional split Hopkinson bar to test high strength steel with high strain rates .The specimen was forming from thin walls with two hexagonal ends. The specimens tested at different angles of twists, the samples were tested at the many angles of twist $\left(10^{\circ}, 8^{\circ}, 4^{\circ}, 1.5^{\circ}\right)$ at room temperature. One of the samples testing at $10^{\circ}$ angle of twist under temperature $500^{\circ} \mathrm{C}$ and $200^{\circ} \mathrm{C}$. The result given that the shear (stress, strain) increased with increased angle of the twist and shear stress decreased with increased temperature at the same angle of twist $10^{\circ}$. Also using Johnson cook to simulation the result based on the experimental test. Ali Majid Ibraheem (2015) [6] using split Hopkinson Pressure bar (SHPB) in compression test with thermal effect. Used epoxy resin and fiber-glass / epoxy composite and added three types of nano particles were carbon black (N220), alumina (Al203) and s-glass. The nano particles added with different weight fraction $2 \%$ and $4 \%$. It used two different temperature to test samples were at room temperature and $150^{\circ} \mathrm{C}$. The result showed 
that the dynamic stress and strain decreased with temperature $150{ }^{\circ} \mathrm{C}$ while increased with addition nano particles to fiber-glass/epoxy composite where the nano particles improved the values of strain rate, strain, stress .In the end adding 4\% nano particle (carbon black, alumina and s-glass) to composite material improved strain rate, strain, stress greater than addition $2 \%$ nano particles. Finally used Johnson Cook model in the theoretical analysis to simulation the experimental work, where it was found error percentages less $15 \%$.the aim of this study focused on

1. The effect of addition nano particles (alumina, black carbon) in fiber glass/epoxy composite under high strain rate torsion using torsional split Hopkinson bar apparatus.

2. The effect of different temperatures (Tr, T75, T100) and different humidity (Hr, H75, H90) on composite and nanocomposite material under high strain rate torsion.

3. Explained the theoretical analysis using Johnson Cook model and modified Johnson Cook model by adding new Parameter (humidity parameter) to explained effect of humidity that it was calculated by dependent on the practical experimental.2. Materials and Methods

\section{Experimental Work}

\subsection{Material Properties}

In present work the composite material content from fiber glass and epoxy resin (Sikadur 52) and nano particle (alumina and carbon black) as shown in figures $(1,2,3)$, so in Table (1) shows the properties of epoxy resin ,Table (2) shows list of the properties of fiberglass and Table (3) Properties of Nanoparticle which were used in the experimental work.

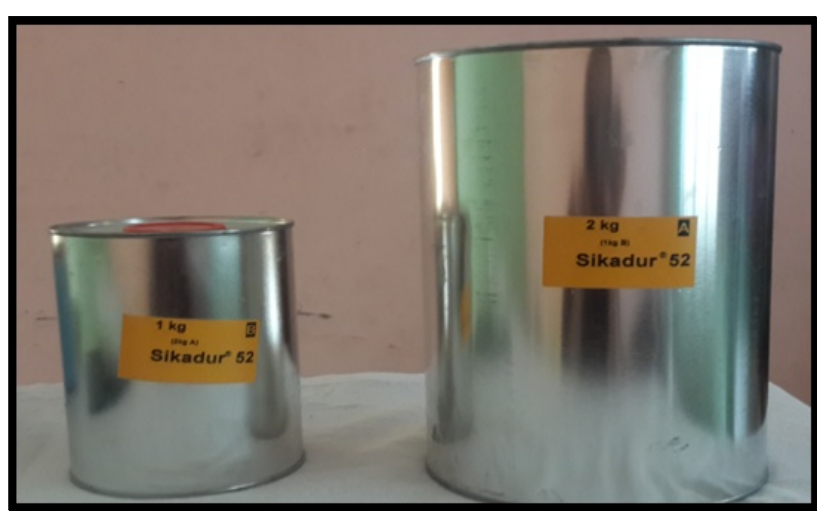

Figure 1. The Epoxy and Hardener (Sikadur 52) Image

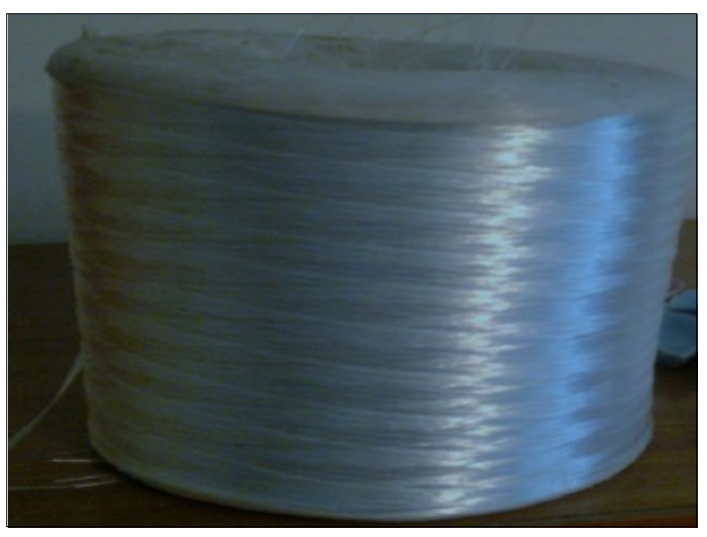

Figure 2. The Fiber Glass Image

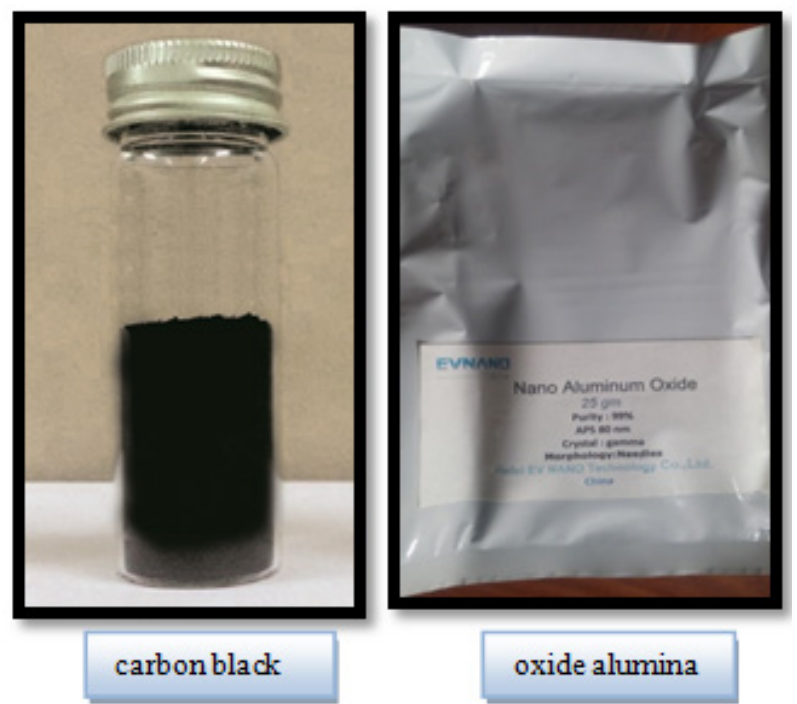

Figure 3. The Nano particles Image

Table 1. The Properties of Epoxy (Sikadur 52) which used in This Work according to Characteristics of The Company Product [7]

\begin{tabular}{|c|c|}
\hline PROPERTIES & VALUES \\
\hline Density & $1.1 \mathrm{~kg} /$ litre \\
\hline Compressive strength & $53 \mathrm{MPa}$ \\
\hline Tensile strength & $37 \mathrm{MPa}$ \\
\hline Flexural Strength & $61 \mathrm{MPa}$ \\
\hline Elastic modulus & $3,500 \mathrm{MPa}$ \\
\hline Thermal Expansion Coefficient & $89 \times 10-6 \mathrm{per}{ }^{\circ} \mathrm{C}$ \\
\hline Mix ratio (by weight) & $2: 1$ \\
\hline
\end{tabular}

Table 2. The Mechanical Properties for Fiber Glass

\begin{tabular}{|c|c|}
\hline PROPERTIES & VALUES \\
\hline Density & $2.45 \mathrm{~g} / \mathrm{cm}^{3}$ \\
\hline Tensile strength & $3,450 \mathrm{MPa}$ \\
\hline Modulus of elasticity & $72,4 \mathrm{Gpa}$ \\
\hline \% Ult. elongation & 5 \\
\hline
\end{tabular}


Table 3. The Properties for nano particle

\begin{tabular}{|c|c|c|}
\hline PROPERTIES & $\begin{array}{c}\text { VALUES } \\
\text { (Alumina) }\end{array}$ & $\begin{array}{c}\text { VALUES } \\
\text { (Nano Carbon) }\end{array}$ \\
\hline Density & $>3.7$ & $355 \pm 20$ \\
\hline O.D.(nm) & $(20-50) \mathrm{nm}$ & $(10-25) \mathrm{nm}$ \\
\hline Purity & $99 \%$ & $95 \%$ \\
\hline Color & White & Black \\
\hline
\end{tabular}

\subsection{Preparation of Samples}

Several steps have been taken to manufacture samples as below:

\section{Determined the Weight Fraction of Fiber}

The weight fraction of specimen that used in the test is $W_{F}=25 \%$. The details are shown in the table (4)

Table 4. The Groups of Specimens that tested

\begin{tabular}{|c|c|c|c|c|}
\hline GROUPS & $\begin{array}{c}\text { Epoxy } \\
\%\end{array}$ & $\begin{array}{c}\text { Fiber glass } \\
\%\end{array}$ & $\begin{array}{c}\text { Nano Alumina } \\
\%\end{array}$ & $\begin{array}{c}\text { Nano } \\
\text { Carbon black } \\
\%\end{array}$ \\
\hline G1 & 75 & 25 & 0 & 0 \\
\hline G2 & 73 & 25 & 0 & 2 \\
\hline G3 & 71 & 25 & 2 & 0 \\
\hline
\end{tabular}

\section{Specimen Geometry}

The specimen used with specific dimensions as shown in figure(4).

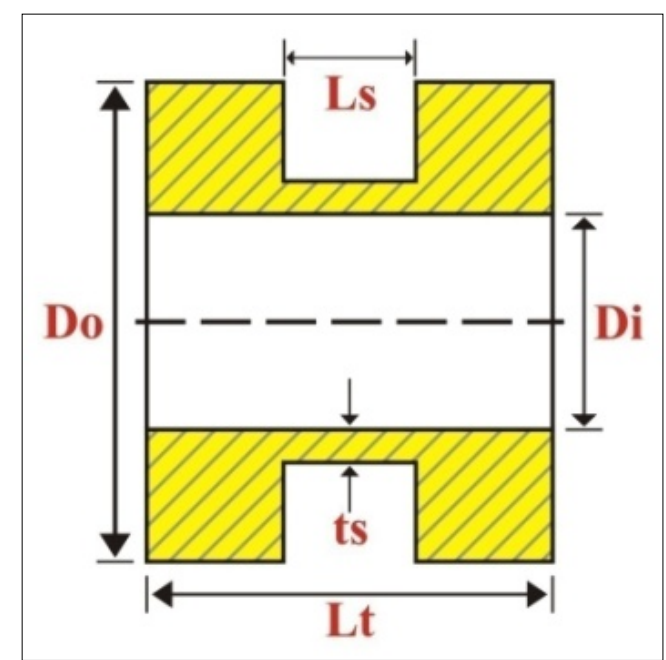

where $\mathrm{Do}=18 \mathrm{~mm}, \mathrm{Di}=8 \mathrm{~mm}, \mathrm{Ds}=12 \mathrm{~mm}, \mathrm{ts}=2 \mathrm{~mm}, \mathrm{Lt}=14 \mathrm{~mm}, \mathrm{Ls}=$ $3.5 \mathrm{~mm} \cdot[8]$

Figure 4. The specimen

\section{Molding and Cutting}

Consist from many steps which is

1. used glass mold cylindrical shape with opened end to molding the specimen have the dimensions (internal diameter and a length $18 \mathrm{~mm}, 150 \mathrm{~mm}$ respectively ,Lubricating the inner walls of the mold with material adhesion blocker then the fiber glass with are arranged in the mold in the homogenous as shown in figure (5).

2. Added nano particles to epoxy (after weight them ) then mixed manually at $25 \mathrm{c}^{\circ}$ for (3 to10) minutes until the mixture become homogeneous in glass box as shown in figure (6) then Adding the hardener to the epoxy-nano mixture then mixing good by hand as shown in figure (7). the mixing with ratio $(2: 1)$ by using the mixer for 10 minutes by slowly to mix the mixture as shown in figure(8), finally Using ultrasonic device to eliminate the existing void in the mixture for 5 minutes as shown in figure (9)

3. The mixture poured into the mold to filling the mold and leaves from 24 to 48 hours to solidification then the samples are cut by using lathe machine on the shape as shown figure (10).

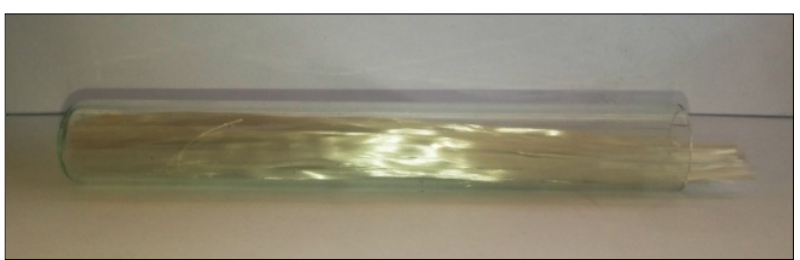

Figure 5. Arrangement Fiber Glass in The Mold



Figure 6. Added Nano Particles to Epoxy

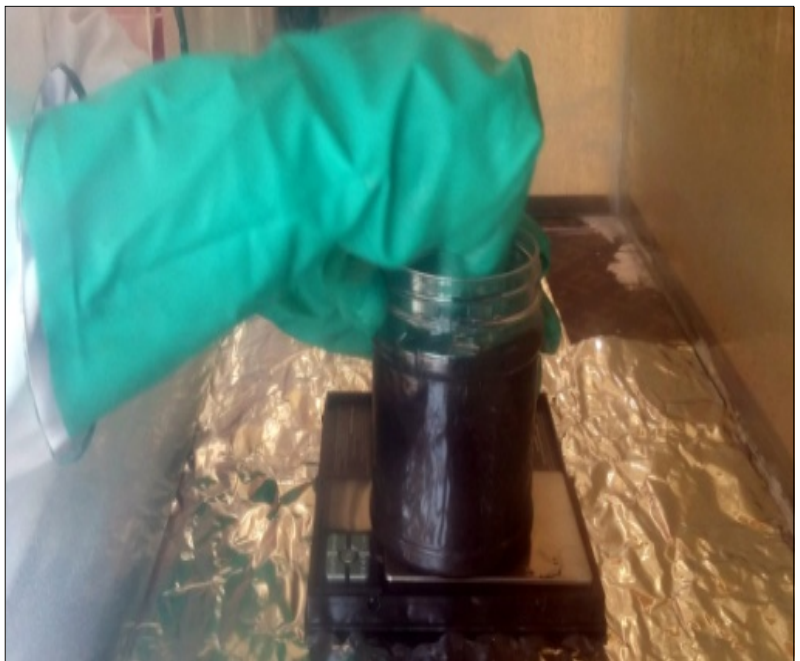

Figure 7. Mixed The Epoxy and Nano Particles by Hand 


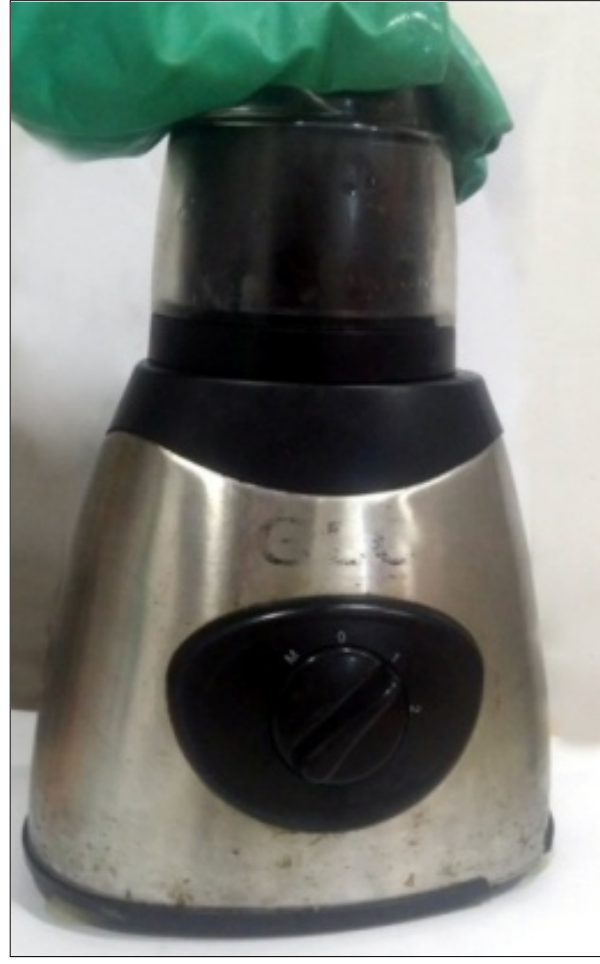

Figure 8. The Mixer

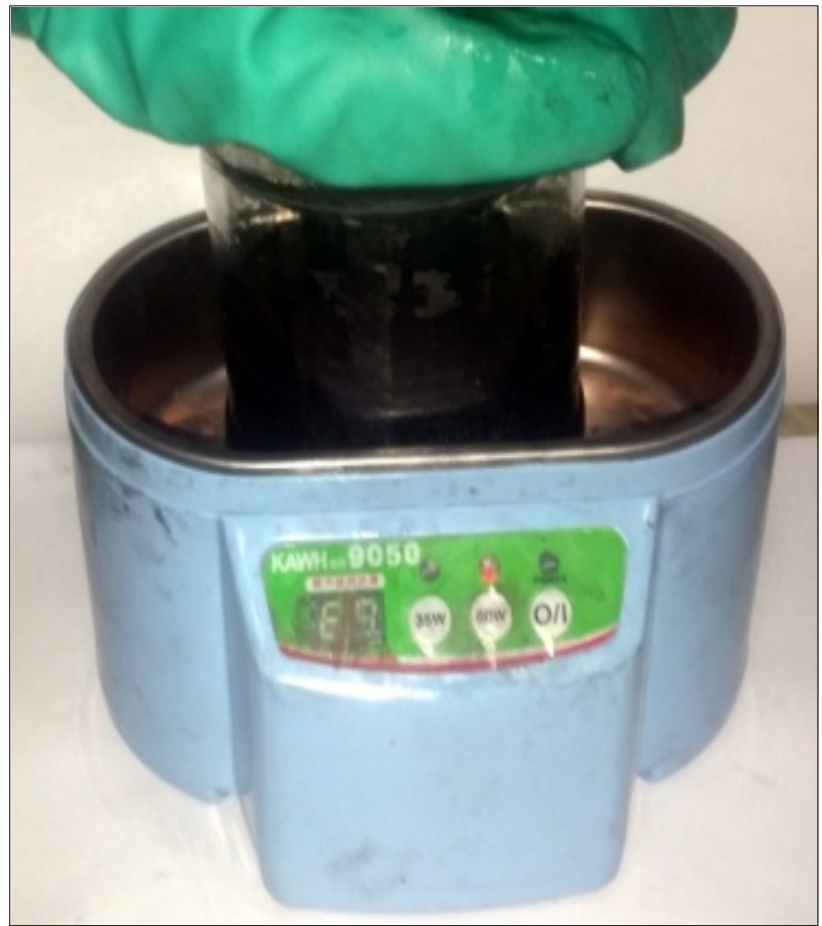

Figure 9. The Ultrasonic Device

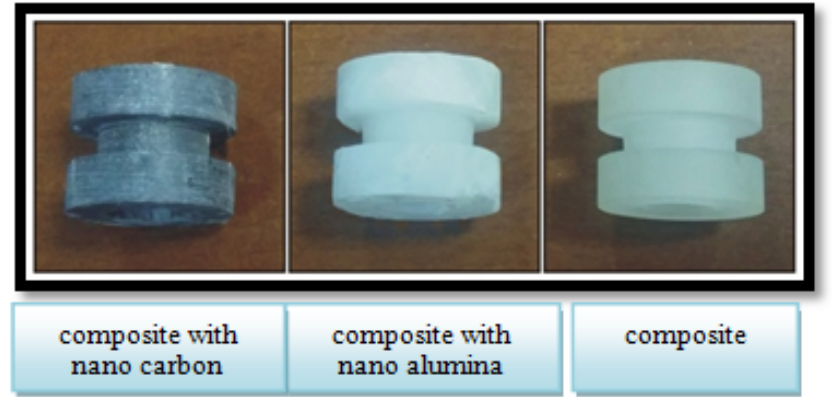

Figure 10. The Image of Specimens

\subsection{Dynamic Test}

In this study is used split Hopkinson torsion bar to test the samples with high strain rates. The split Hopkinson torsion bar consist from incident bar, transmitted bar, Clamp system, Support Block (Brackets), Adapters, Torque Generating Mechanism, End Fixing, Bushing and steel channel [8], so it used measurement system that consist from two couple of strain gage which bonded in incident band transmitted bar then connected to Wheatstone bridge that connect with digital oscilloscope finally connect the digital oscilloscope with personal computer ( laptop ) as shown in figure (11)

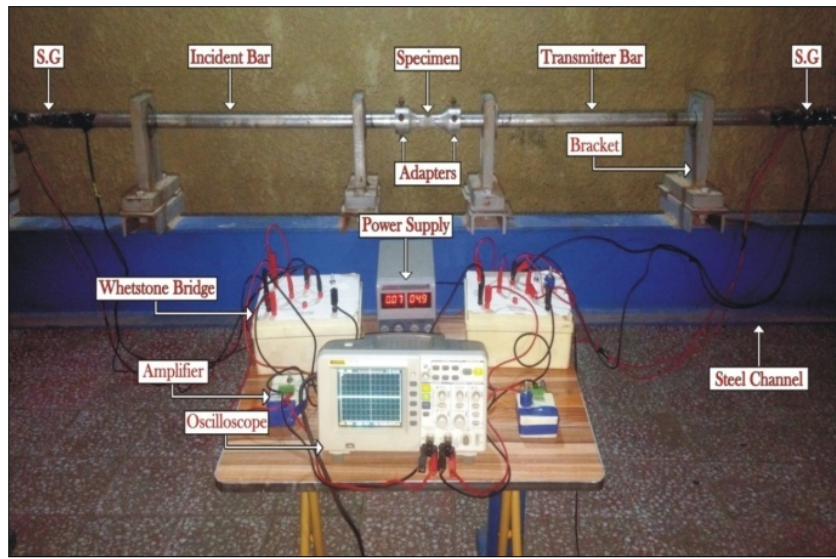

Figure 11. Image of The Torsion Split Hopkinson Bar at Test

To provide different environmental conditions to study effect environmental conditions (temperature and humidity) was used accelerated weathering chamber [9] where the samples are placed for five hours under the effect of heat and humidity is different as shown in the table (5) 
Table 5. Classification The Specimen Tested

\begin{tabular}{|c|c|c|}
\hline Groups & Temperature $\left({ }^{\circ} \mathbf{C}\right)$ & Humidity Ratio (\%) \\
\hline G1,G2, G3 & ${ }^{\circ} \mathbf{C}$ & \% \\
\hline $\mathrm{TrHr}$ & $\mathrm{T}_{\mathrm{ROOM}}$ & $\mathrm{H}_{\mathrm{ROOM}}$ \\
\hline $\mathrm{TrH75}$ & $\mathrm{T}_{\mathrm{ROOM}}$ & 75 \\
\hline $\mathrm{TrH} 90$ & $\mathrm{~T}_{\mathrm{ROOM}}$ & 90 \\
\hline $\mathrm{T} 75 \mathrm{Hr}$ & 75 & $\mathrm{H}_{\mathrm{ROOM}}$ \\
\hline $\mathrm{T} 75 \mathrm{H} 75$ & 75 & 75 \\
\hline $\mathrm{T} 75 \mathrm{H} 90$ & 75 & 90 \\
\hline $\mathrm{T} 100 \mathrm{Hr}$ & 100 & $\mathrm{H}_{\mathrm{ROOM}}$ \\
\hline $\mathrm{T} 100 \mathrm{H} 75$ & 100 & 75 \\
\hline $\mathrm{T} 100 \mathrm{H} 90$ & 100 & 90 \\
\hline
\end{tabular}

after the samples are tested with split Hopkinson torsion apparatus bar with angle of twist $10^{\circ}$.

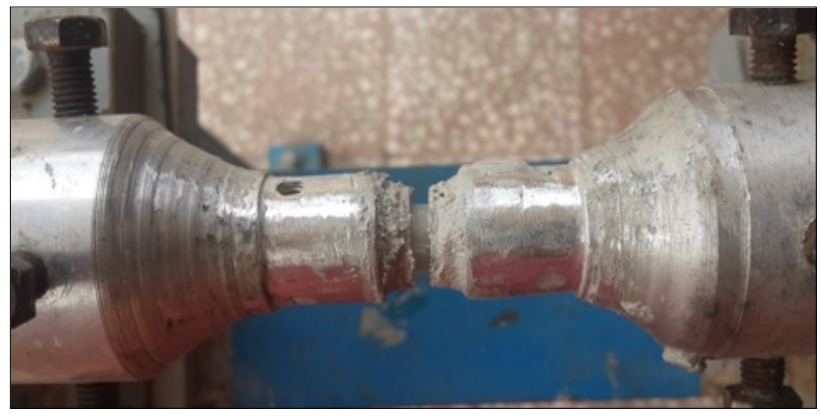

Figure 12. The Specimen Between The Grips before Testing.

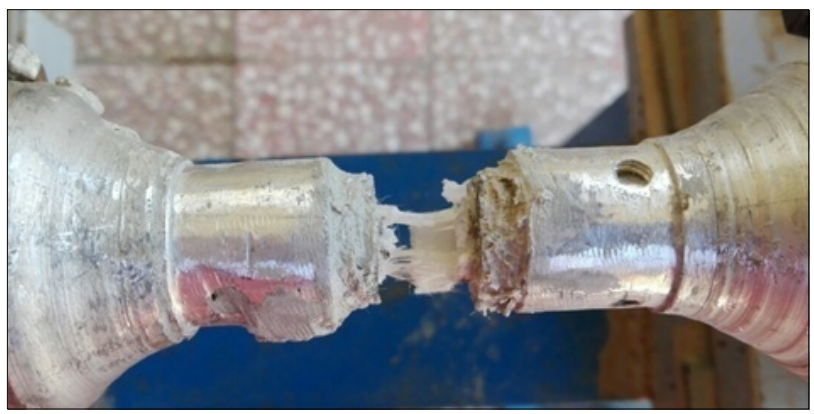

Figure 13. The Specimen after Testing

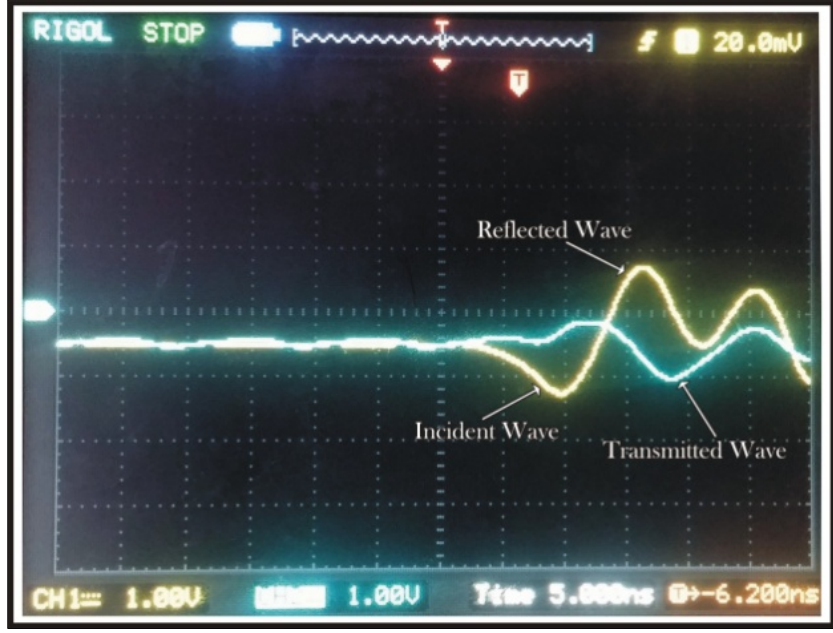

Figure 14. The Image of The Elastic Wave which Recorded by Oscilloscope after Testing

\subsection{Static Test}

The compression test give information about properties of material tested (stress and strain). The shape and the dimensions of specimen was tested accord to (ASTM-D695M-89) standards [10], where Lo/do ratios are 1.5 to 3 therefore used specimen with diameter $18 \mathrm{~mm}$ and length $36 \mathrm{~mm}$ shown figure (15) In this test the specimens tested by using compression test machine (TINIUS OLSEN H50KT) as shown in figure (16)

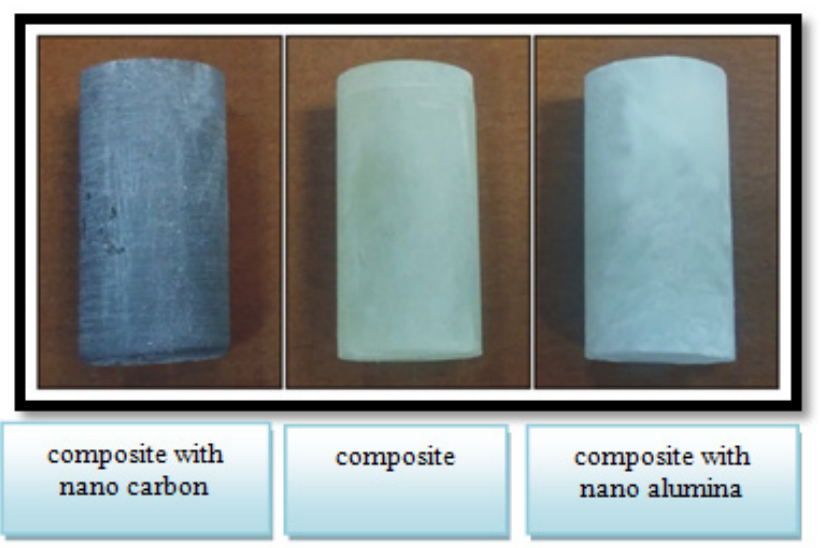

Figure 15. The Specimen Used in Static Test. 


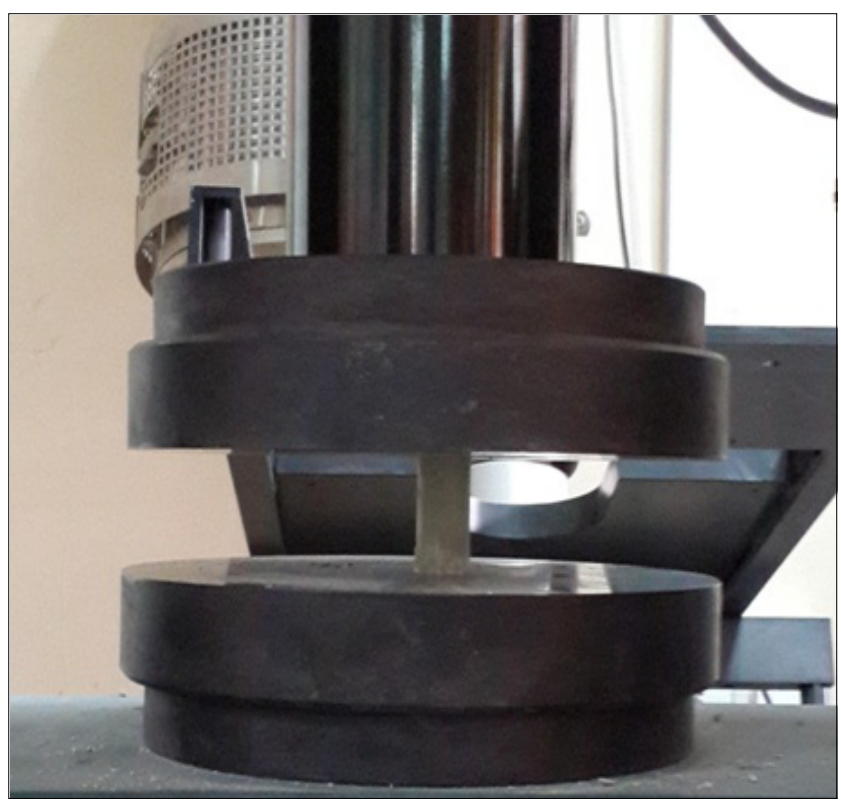

Figure 16. Compression test machine

\subsection{Calculation Shear Stress, Strain-Rate, Strain of the Specimen}

Calculated the shear strain rate, shear strain and shear stress from the elastic wave signals that was captured in incident, transmitted and reflected waves by use two couples of strain gage using equations [5]:

$$
\begin{gathered}
\tau_{S}(t)=\frac{G D^{3}}{8 D_{S}{ }^{2} t_{S}}\left[\gamma_{T}(t)\right] \\
\gamma_{S}(t)=\frac{2 C_{S} D_{S}}{L_{S} D}\left[-\gamma_{R}(t)\right] \\
\gamma_{S}(t)=\frac{2 C_{S} D_{S}}{L_{S} D} \int_{0}^{t}-\gamma_{R}(t) d t
\end{gathered}
$$

\section{Johnson-Cook Constitutive Model and the suggestion of Modification Johnson-Cook Constitutive Mode}

Constitutive model that describes the flow stress depending on strain, strain rate and temperature, to the simulations of deformation at high strain rate used The five-parameter experimental Johnson-Cook (JC) constitutive model [10].The model represents The Johnson-Cook constitutive relation is represent

$$
\sigma=\left[\mathrm{A}+\mathrm{B} \in \mathrm{p}^{\mathrm{n}}\right]\left[1+\mathrm{C} \operatorname{Ln} \dot{\varepsilon}^{*}\right]\left[1-\mathrm{T}^{* \mathrm{~m}}\right]
$$

Where $\epsilon p:$ it is represented the plastic strain equivalently .

A: it is represented the yield stress which correspond to $0.2 \%$ displacement (offset) strain. The constant $\mathrm{A}$ is determined from the stress-strain curve where it is plotted an offset $0.2 \%$ strain at strain rate $\sim 1 / \mathrm{s}$.
$\mathrm{B}$ and $\mathrm{n}$ : represented the strain hardening effects of the material. They are determined from plotted the Logarithmic plastic strain vs. plastic strain.

$\mathrm{C}$ : it is represented the strain rate effect (strain rate sensitivity).It is determined as slope the linear of $\mathrm{Ln}$ (strain rate) vs. (Dynamic stress/ Static stress). And $\dot{\varepsilon}^{*}$ $=\dot{\varepsilon} / \dot{\varepsilon}^{\circ}$, Where $\dot{\varepsilon}^{\circ}$ is the reference strain-rate (static strain rate ) and $\dot{\varepsilon}$ is the strain-rate of sample at testing $\mathrm{T}^{*}:$ it is represented the homologous temperature $=$ $\left(\mathrm{T}_{\text {test__}} \mathrm{T}_{\text {ROOM }}\right) /\left(\mathrm{T}_{\text {MELT }}-\mathrm{T}_{\text {ROOM }}\right)$ where $\mathrm{m}$ : it is represented thermal effect and is determined from plotted of the relation between $\mathrm{Ln}(\mathrm{T} *)$ and $\operatorname{Ln}(1 \sigma$ heating $/ \sigma R T)$ for thermal effect and on the condition of $\dot{\varepsilon}=\dot{\varepsilon}^{\circ}$ and $\epsilon \mathrm{p}=0$.

The first expression of brackets was represented the stress in terms of strain when $\dot{\varepsilon}^{*}=1.0$ and $\mathrm{T}^{*}=0$. The second and third expression of brackets was represented the strain rate and temperature effects respectively through constant c, m and k [11]. Details will be clarified in chapter five.

The von Mises yield criterions are used to convert the shear stress into equivalent stress using the relations before used it in Johnson-Cook Constitutive model [12]:

$$
\begin{gathered}
\sigma=\sqrt{3} \tau_{\mathrm{s}} \\
\varepsilon \varepsilon \mathbf{\epsilon}=\frac{\gamma_{\mathrm{s}}}{\sqrt{3}} \\
\dot{\varepsilon}=\frac{\gamma_{\mathrm{s}}}{\sqrt{3}}
\end{gathered}
$$

finally to describe the effect of the humidity on the materials It was submitting a suggestion to modify Johnson Cook by adding constants represented the humidity effect. The "(4)," was modified to the equation "(8),"

$$
\sigma=\left[\mathrm{A}+\mathrm{B} \in \mathrm{p}^{\mathrm{n}}\right][1+\mathrm{C} \text { Ln } \dot{\varepsilon}]\left[1-\mathrm{T}^{* \mathrm{~m}}\right]\left[1-\mathrm{H}^{* \mathrm{~K}}\right]
$$

$\mathrm{H}^{*}$ It is reperesented the content of humidity $H^{*}=\left(M_{f}-M_{i}\right) / M_{i}$, Where $M_{f}, M_{i}$ is weight of specimen after and before subject to humidity effect. $\mathrm{k}$ represented is the humidity effect, it can determined from plotted of the relation between the $\mathrm{Ln}(\mathrm{H} *)$ and $\mathrm{Ln}$ $(1-\sigma$ humidity $/ \sigma \mathrm{RH})$ on the condition $\mathrm{T}^{*}=0, \dot{\varepsilon}=\varepsilon^{\circ} *$ and $\epsilon_{p}=0$

\section{Results}

\subsection{Dynamic Tests Results}

In figure (17) to (28), it can be seen that the shear stress and shear strain decreased with increased temperature and humidity with different percentage and the shear strain rate decreased with increased temperature and humidity that explained in table (6) 


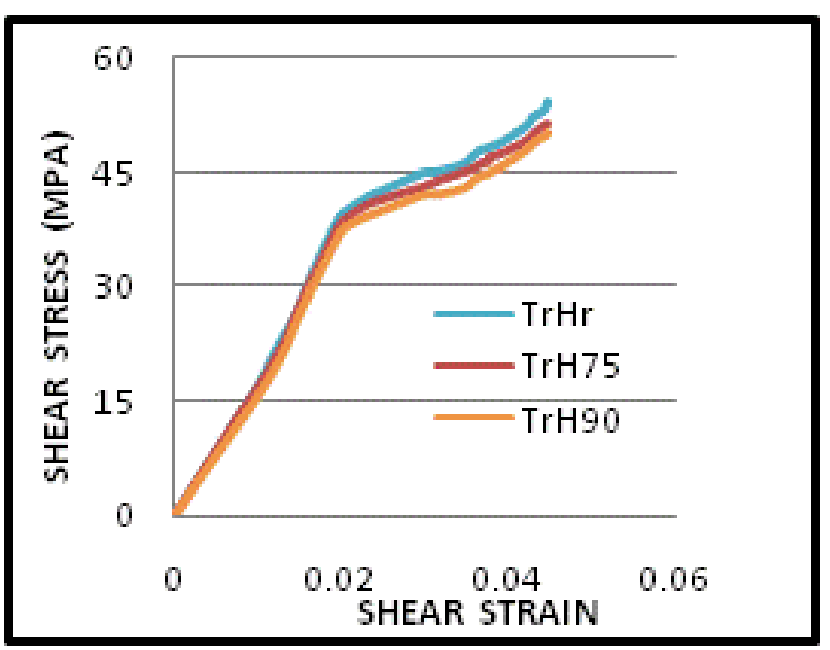

Figure 17. The Dynamic Shear (Stress-Strain) Behavior of G1 at the Room Temperature

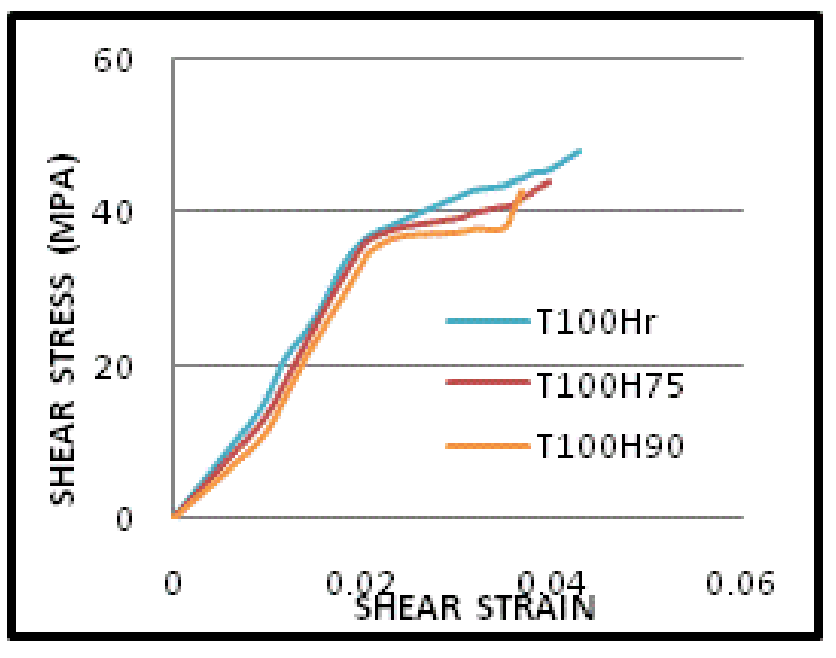

Figure 18. The Dynamic Shear (Stress-Strain) Behavior of G1 at $100 \mathrm{c}^{\circ}$ with increased Humidity

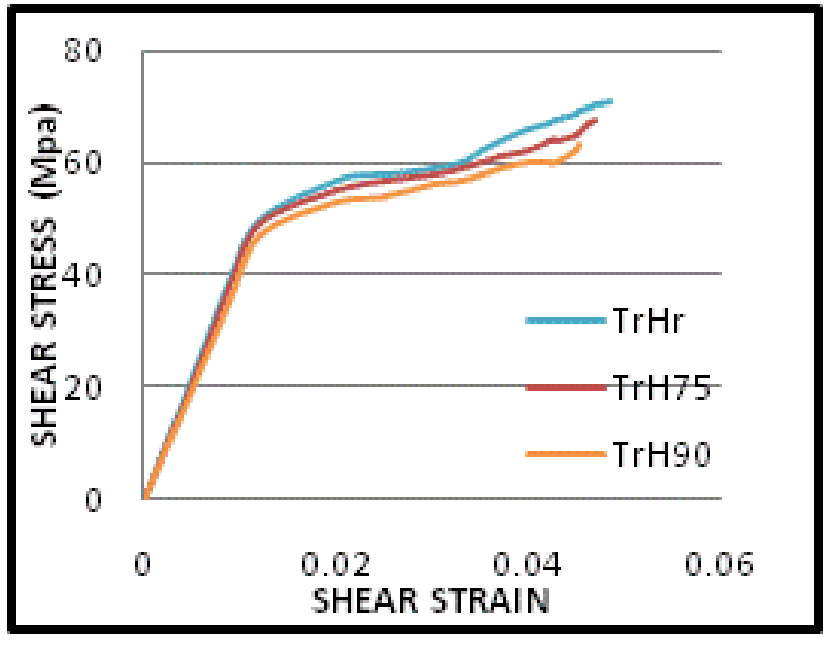

Figure 19. The Dynamic Shear (Stress-Strain) Behavior of G2 at The Room Temperature with increased Humidity

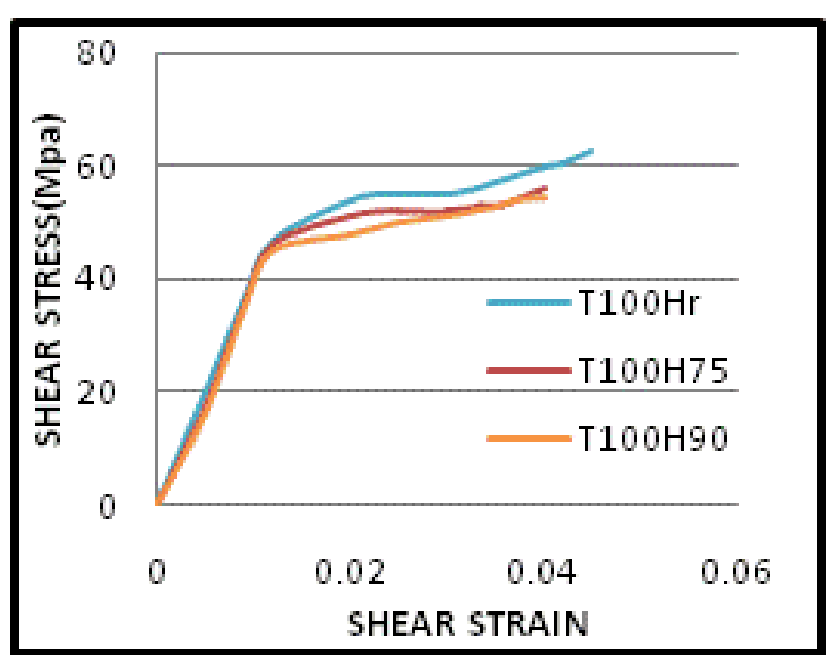

Figure 20. The Dynamic Shear (Stress-Strain) Behavior of G2 at $100 \mathrm{c}^{\circ}$ with increased Humidity

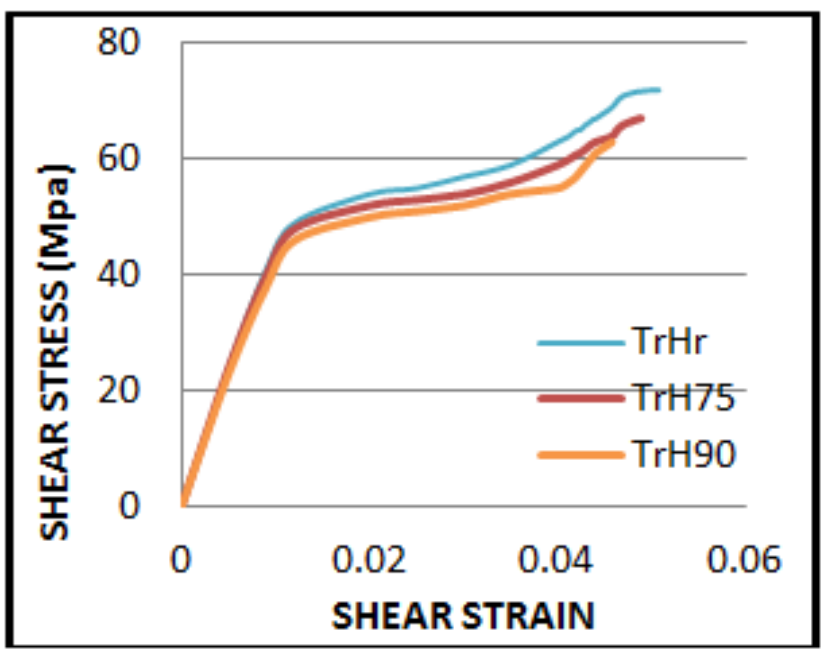

Figure 21. The Dynamic Shear (Stress-Strain) Behavior of G3 at The Room Temperature with increased Humidity

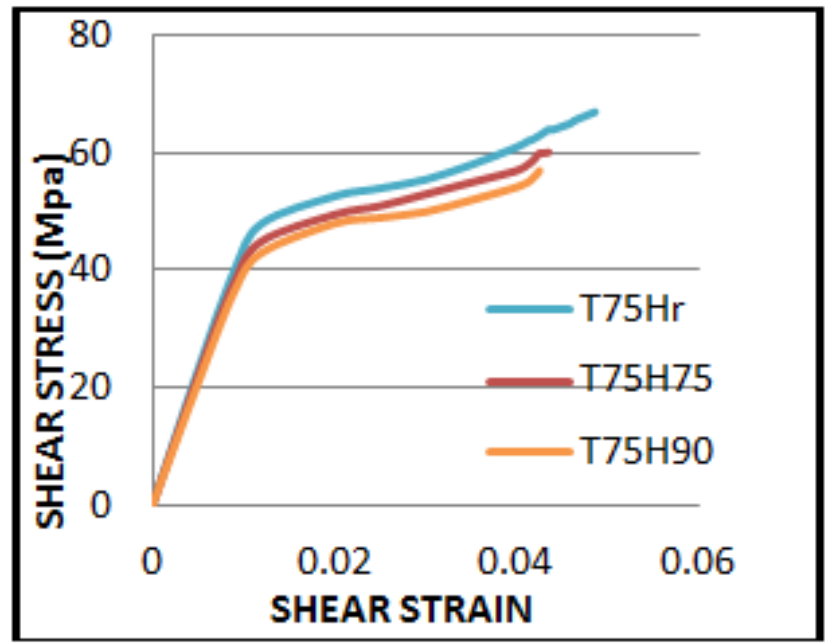

Figure 22. The Dynamic Shear (Stress-Strain) Behavior of G3 at Temperature $75 \mathrm{c}^{\circ}$ with increased Humidity 


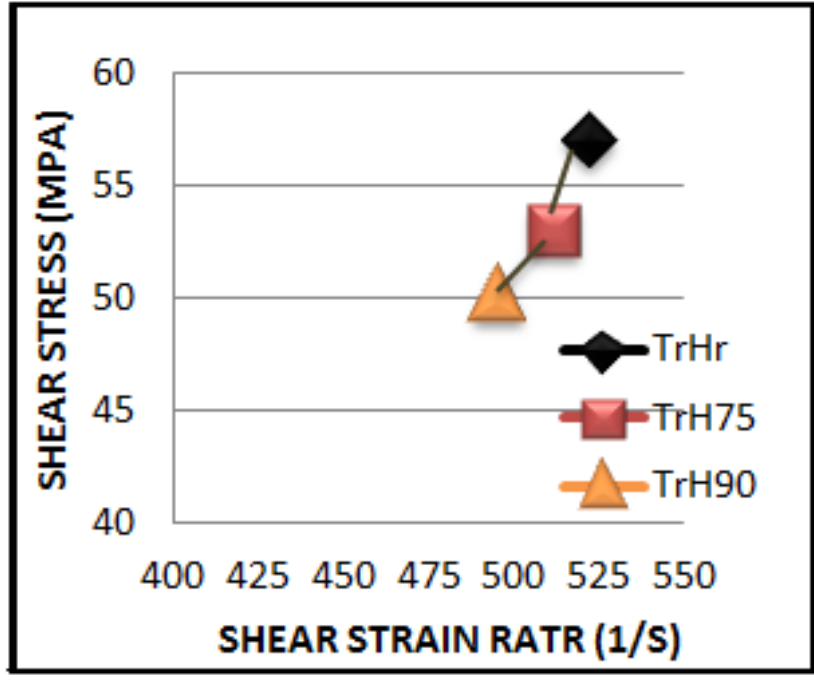

Figure 23. The Variations of Maximum Shear Strain Rate with Shear Stress of G1 at The Room Temperature with increased Humidity

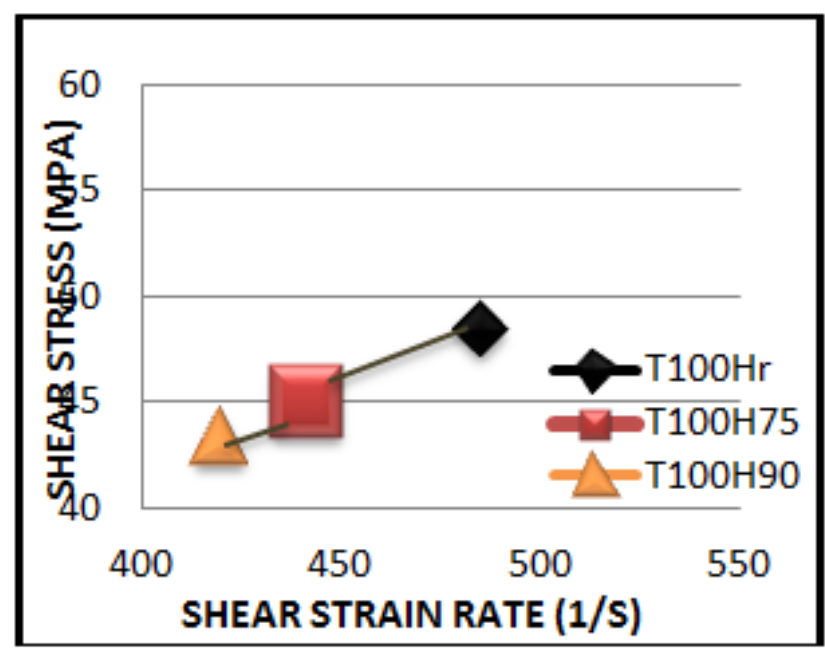

Figure 24. The Variations of Maximum Shear Strain Rate with Shear Stress of G1 at Temperature $100 \mathrm{c}^{\circ}$ with increased Humidity

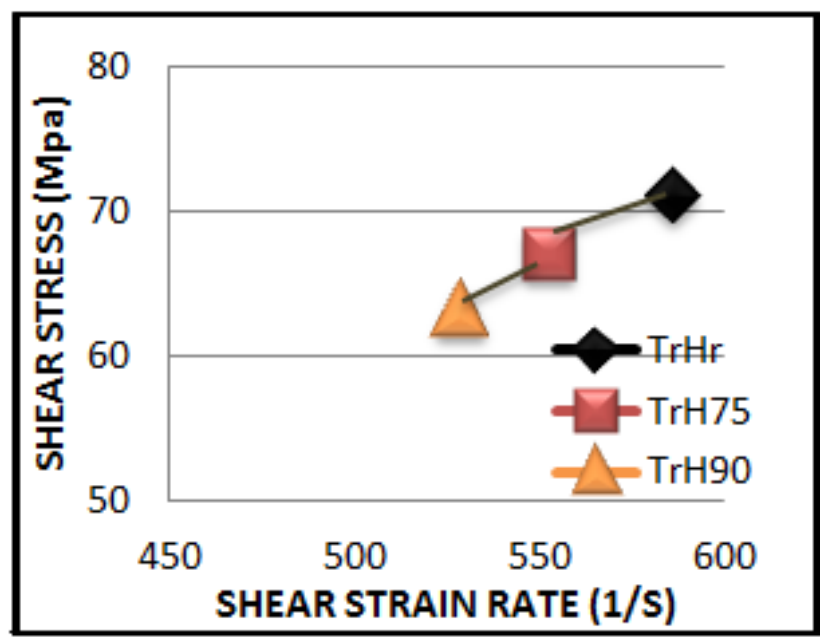

Figure 25. The Variations of Maximum Shear Strain Rate with Shear Stress of G2 at The Room Temperature with increased Humidity

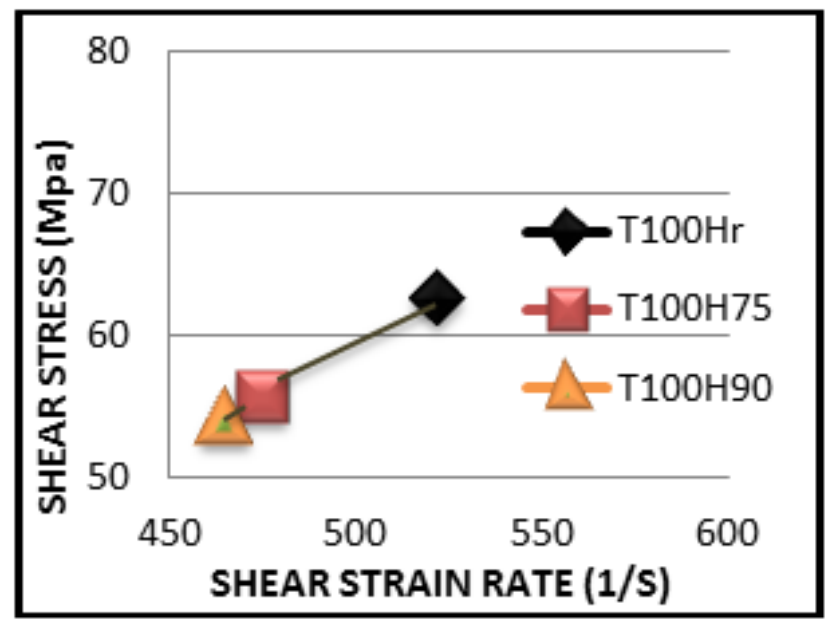

Figure 26. The Variations of Maximum Shear Strain Rate with Shear Stress of $\mathrm{G} 2$ at The Temperature $100 \mathrm{c}^{\circ}$ with increased Humidity

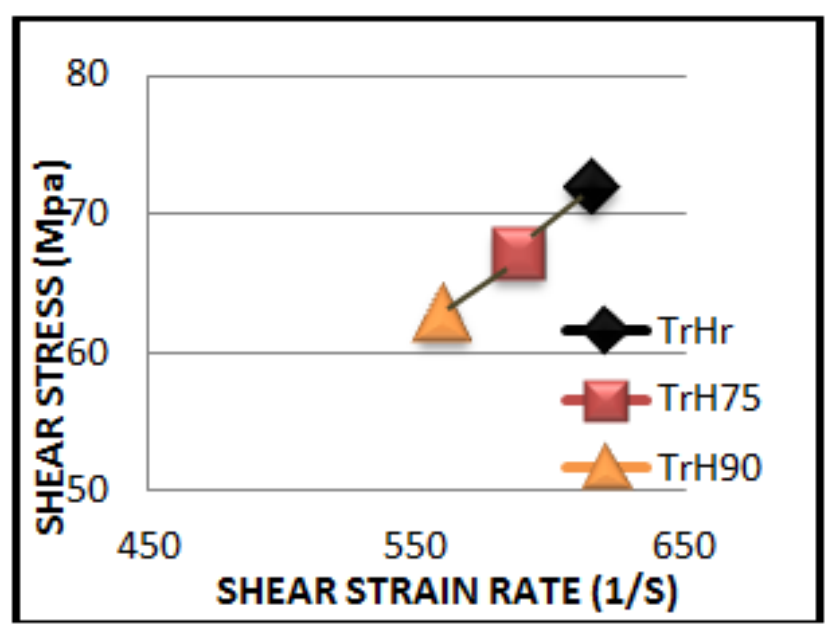

Figure 27. The Variations of Maximum Shear Strain Rate with Shear Stress of G3 at The Room Temperature with increased Humidity

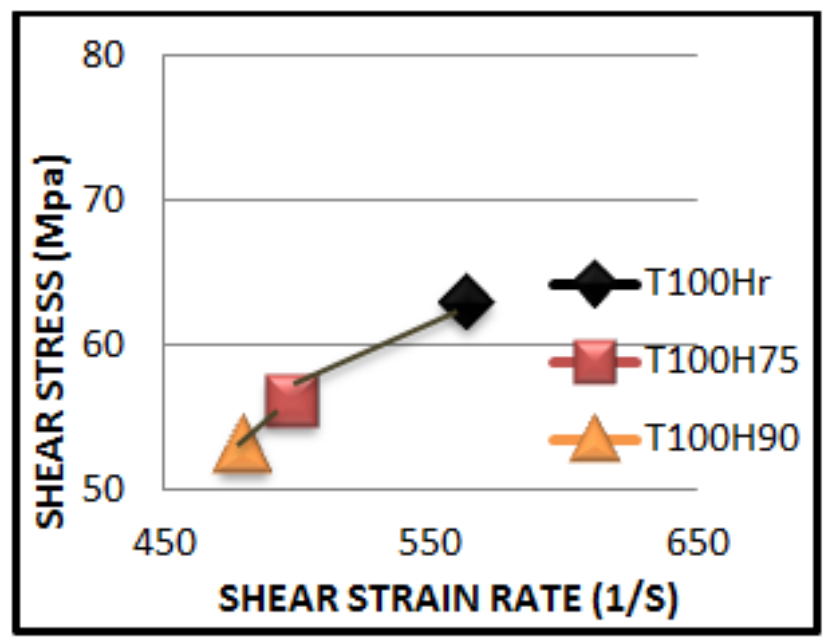

Figure 28. The Variations of Maximum Shear Strain Rate with Shear Stress of G3 at The Temperature $100 \mathrm{c}^{\circ}$ with increased Humidity 
Table 6. The Experimental Maximum Values of shear (Stress, Strain, Strain rate) for Fiber Glass/Epoxy Composite and nano composite at Different Temperature and Humidity

\begin{tabular}{|c|c|c|c|c|}
\hline $\begin{array}{c}\text { The } \\
\text { materials } \\
\text { groups }\end{array}$ & $\begin{array}{c}\text { Temperature and } \\
\text { humidity } \\
\text { condition }\end{array}$ & $\begin{array}{c}\text { Shear } \\
\text { stress } \\
\text { Mpa }\end{array}$ & $\begin{array}{l}\text { Shear } \\
\text { strain }\end{array}$ & $\begin{array}{l}\text { Shear } \\
\text { strain } \\
\text { rate } 1 / \mathrm{s}\end{array}$ \\
\hline \multirow{6}{*}{ G1 } & $\mathrm{TrHr}$ & 57 & 0.0468 & 530 \\
\hline & TrH75 & 53 & 0.0452 & 512 \\
\hline & TrH90 & 50.08 & 0.0439 & 490 \\
\hline & $\mathrm{T} 100 \mathrm{Hr}$ & 49 & 0.0431 & 485 \\
\hline & T100H75 & 45 & 0.0398 & 441 \\
\hline & T100H90 & 43 & 0.0379 & 420 \\
\hline \multirow{6}{*}{ G2 } & $\mathrm{TrHr}$ & 71.2 & 0.0483 & 586 \\
\hline & TrH75 & 67 & 0.0468 & 553 \\
\hline & TrH90 & 63.1 & 0.0453 & 529 \\
\hline & $\mathrm{T} 100 \mathrm{Hr}$ & 62.7 & 0.0448 & 522 \\
\hline & $\mathrm{T} 100 \mathrm{H} 75$ & 55.8 & 0.042 & 475 \\
\hline & T100H90 & 54.25 & 0.0418 & 465 \\
\hline \multirow{6}{*}{ G3 } & $\mathrm{TrHr}$ & 72 & 0.0508 & 615 \\
\hline & TrH75 & 67.12 & 0.0489 & 588 \\
\hline & TrH90 & 62.64 & 0.04581 & 560 \\
\hline & $\mathrm{T} 100 \mathrm{Hr}$ & 63 & 0.0463 & 563 \\
\hline & $\mathrm{T} 100 \mathrm{H} 75$ & 56.16 & 0.04198 & 498 \\
\hline & T100H90 & 53.78 & 0.0412 & 480 \\
\hline
\end{tabular}

\subsection{Static Tests Results for All Groups of Materials}

The theoretical model based on (Johnson- Cook equation) using the static compression test results to calculate the constant of (Johnson- Cook equation) to comparing between the theoretical and experimental results. The value of the maximum strain and stress of material from static tests were shown in table (7).

Table 7. Experimental Results of Static Test for All Group with The Humidity and Temperature at Room Condition of Composite at at a strain rate of $\sim 1 / \mathrm{s}$

\begin{tabular}{|c|c|c|}
\hline Groups & Max stress (Mpa) & Max Strain \\
\hline G1 & 123 & 0.02216 \\
\hline G2 & 181 & 0.0229 \\
\hline G3 & 193 & 0.0243 \\
\hline
\end{tabular}

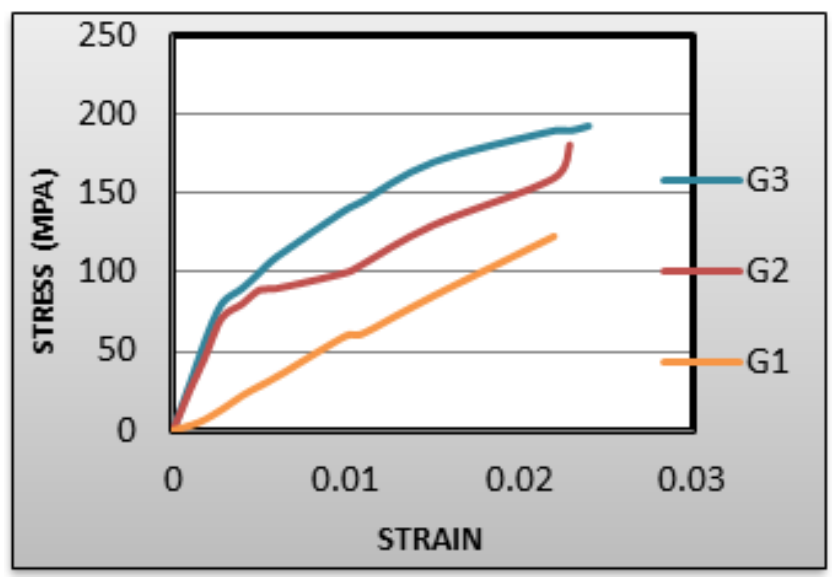

Figure 29. Comparison for Static Compression Stress- Strain Behavior with the Humidity and Temperature at Room Condition of All Groups

\subsection{Analytical Assessment of Results (The equation of Johnson - Cook)}

The dynamic shear test results for all groups of tested materials by using Johnson-cook constitutive model. It was used the Johnson-Cook constitutive model to specify the theoretical stress-strain behavior for G4 in all condition. Depended on Johnson-Cook constitutive model, the following equation "(9)," can obtain for G3 depended on equation "(4),":

$$
\boldsymbol{\sigma}=\left[71+190 \epsilon^{\mathbf{0 . 5 0 5}}\right][1+0.068 \operatorname{Ln} \dot{\boldsymbol{\varepsilon}}]\left[1-\mathbf{T}^{* 1.76}\right]
$$

Table 8. Lists the Values of Johnson-Cook Constitutive Model for All Groups

\begin{tabular}{|c|c|c|c|c|c|c|}
\hline Groups & A & B & C & $\mathrm{n}$ & $\mathrm{m}$ & $\mathrm{k}$ \\
\hline G1 & 61 & 126 & 0.057 & 0.91 & - & - \\
\hline G2 & 74 & 163 & 0.065 & 0.455 & - & - \\
\hline G4 & 71 & 190 & 0.068 & 0.505 & 1.76 & 0.275 \\
\hline
\end{tabular}

To explain the effect of humidity (moisture content ) on G4 where it has been modified Johnson-cook constitutive model and added a new part representing the effect of moisture $\left[1-\mathrm{H}^{* \mathrm{~K}}\right]$, at the condition (strain rate of $\sim 1 / \mathrm{s}$, When $€=0$, the room temperature) where the equation "(9)," in the form :

$$
\sigma=\mathrm{A}\left[1-\mathrm{H}^{* \mathrm{~K}}\right]
$$


The table(9) gives the experimental static results for G4 at different humidity (moisture content) that need to calculate $\mathrm{k}$, and table (10) gives the details of calculation $H^{*}$ where $H^{*}=\frac{M_{\mathrm{f}}-M_{\mathrm{i}}}{M_{\mathrm{i}}}$

Table 9. The Values of Stress in Experimental Static Results for G4 at Variable Humidity and room temperature

\begin{tabular}{|c|c|c|c|c|}
\hline Humidity \% & 60 & 75 & 90 & 95 \\
\hline Stress(Mpa) & 190.87 & 187 & 179 & 178.2 \\
\hline
\end{tabular}

Table 10. Details for $x, y$ coordinate to Determine The value of $(k)$ for G4

\begin{tabular}{|c|c|c|c|c|c|}
\hline $\begin{array}{c}\text { Humid- } \\
\text { ity } \%\end{array}$ & $\begin{array}{c}\mathrm{W}_{\mathrm{i}} \\
\mathrm{gm}\end{array}$ & $\begin{array}{c}\mathrm{W}_{\mathrm{f}} \\
\mathrm{gm}\end{array}$ & $\mathrm{H}^{*}$ & LnH $^{*}$ & $\begin{array}{c}\text { Ln } \\
(1-\sigma \text { humidi } \\
\text { ty } / \sigma \mathrm{RH})\end{array}$ \\
\hline 60 & 11.55 & 11.564 & 0.00124 & -4.50 & -6.69 \\
\hline 75 & 11.55 & 11.565 & 0.00136 & -3.47 & -6.450 \\
\hline 90 & 11.55 & 11.573 & 0.002 & -2.623 & -6.2146 \\
\hline 95 & 11.55 & 11.574 & 0.0021 & -2.56 & -6.156 \\
\hline
\end{tabular}

The relation between $\mathrm{LnH}^{*}$ and $\mathrm{Ln}(1 \sigma$ humidity $/ \sigma \mathrm{RH})$ can be plotted to evaluate (k) as shown in figure (30).

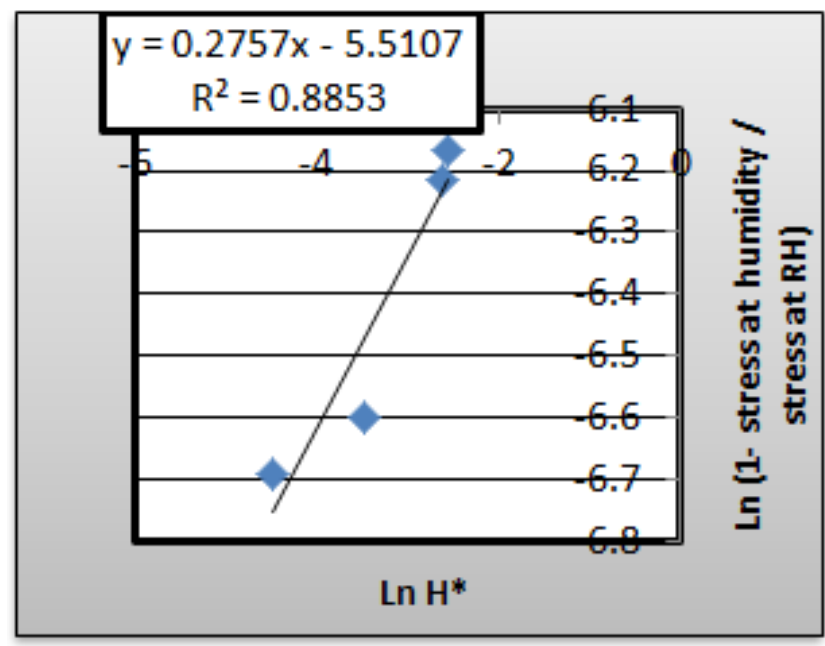

Figure 30. Constant $\mathrm{K}$ Determination

Apply the value of all constant in Johnson-cook constitutive equation where "(9)," became in form "(11)," which represented the Johnson-cook constitutive equation for $\mathrm{G} 4$ in all condition:

$$
\boldsymbol{\sigma}=\left[71+190 \epsilon^{\mathbf{0 . 5 0 5}}\right][1+0.068 \text { Ln } \dot{\boldsymbol{\varepsilon}}]\left[1-\mathbf{T}^{* 1.76}\right]^{*}
$$

Table (11) shows the theoretical values of shear stress at all conditions
Table 11. Lists The Shear Stress Experimental and Theoretical Results of Materials

\begin{tabular}{|c|c|c|c|c|}
\hline Groups & $\begin{array}{c}\text { Experimental } \\
\text { Shear stress } \\
\text { (MPA) }\end{array}$ & $\mathrm{H}^{*}$ & $\begin{array}{c}\text { Theoretical } \\
\text { Shear } \\
\text { stress } \\
\text { (MPA) }\end{array}$ & $\begin{array}{c}\text { Error } \\
\text { Percentages } \\
\%\end{array}$ \\
\hline G1 (TrHr) & 57 & - & 50.71 & 12.4 \\
\hline G2(TrHr) & 71.2 & - & 84.34 & $\mathbf{1 5 . 5}$ \\
\hline G3 (TrHr) & 72 & - & 82.3 & 12.5 \\
\hline G3 (TrH75) & 67.12 & 0.0019 & 76.8 & 12.55 \\
\hline G3(TrH90) & 62.64 & 0.0021 & 57.971 & 8.05 \\
\hline G3(T75Hr) & 66.24 & - & 77.5 & 14.5 \\
\hline G3(T75H75) & 60.12 & 0.0031 & 60.39 & $\mathbf{4 . 4 \times 1 0 ^ { - 3 }}$ \\
\hline G3(T75H90) & 57 & 0.0032 & 56 & 1.78 \\
\hline G3(T100Hr) & 63 & - & 71.8 & 12.25 \\
\hline G3(T100H75) & 56.16 & 0.0034 & 55.6 & 1 \\
\hline G3(T100H90) & 53.78 & 0.0035 & 55.26 & 2.6 \\
\hline
\end{tabular}

\section{Discussion and Conclusions}

\subsection{Discussion}

The results shown that the shear (stress, strain, strain rate ) of G2 and G3 at TrHr more than shear (stress, strain, strain rate) of G1 where they increased with added $2 \%$ nano carbon and nano alumina with percentage ( $24.91 \%$, $3.2 \%, 10.56 \%)$ and $(26.31 \%, 8.5 \%, 16 \%)$ respectively because the nano particles are improved the mechanical and physical properties of the composite so the bonded between atoms became stronger because added nano particles caused increased the interference between the epoxy and nano particles which lead to reduce the movement of polymer [13].so shown that the shear properties (stress, strain ,strain rate) decreased with increasing temperature and humidity of all groups of materials, where it can be seen in behavior of G1 that the shear stress at $(\mathrm{TrHr})$ decreased by rate of $14.03 \%$ with increased temperature to $100 \mathrm{C}^{\circ}$ at $(\mathrm{T} 100 \mathrm{Hr})$ and $(\mathrm{TrHr})$ decreased by rate of $12.4 \%$ with increased humidity ratio to $90 \%$ at (TrH90) so the decreased percentage increasing when increased temperature and humidity ratio together , where dynamic shear stress of ( $\mathrm{TrHr})$ decreased by $21.05 \%$ with increased temperature to T100 and increased humidity to $90 \%$ at (T100H90) because the increasing of the humidity and temperature reduce the properties and increase the movement of the molecules of the composite caused decreasing the bonded between the fiber and matrix ,in addition the high temperature caused leads to increased moisture content Subsequently the substance becomes weaker. 
In the second groups G2 (composite with 2\% nano carbon) behaves the same behavior as the composite material under the effect of temperature and humidity but it decreased with different rates where the dynamic shear stress of $\mathrm{TrHr}$ decreased by $11.73 \%$ with increased temperate to $100 \mathrm{C}^{\circ}$ at $(\mathrm{T} 100 \mathrm{Hr}), \mathrm{G} 2$ at $(\mathrm{TrHr})$ decreased by rate of $11.4 \%$ with increased humidity ratio to $90 \%$ at (TrH90) and decreased by $23.8 \%$ with increased temperature to $\mathrm{T} 100$ and increased humidity to $90 \%$ at (T100H90). finally the dynamic shear stress at ( $\mathrm{TrHr}$ ) of G3 decreased by rate of $13.88 \%$ with increased temperature to $100 \mathrm{C}^{\circ}$ and $13 \%$ with increased humidity to 90 while the dynamic shear stress decreased by $25.3 \%$ at T100H90. In all cases with increased temperature and humidity all materials behaves the same behavior in addition decreased dynamic shear stress because temperature and humidity the shear strain and shear strain rate decreased with different percentage as shown in table (6).

\subsection{Conclusions}

It can be seen that the conclusions as below:

1. For three groups ( unidirectional fiber glass/ epoxy composite, unidirectional fiber glass/ epoxy composite with $2 \%$ nano carbon, unidirectional fiber glass/ epoxy composite with $2 \%$ nano alumina and unidirectional fiber glass/) can be observed in the results of the shear dynamic test that the maximum of the shear strain and shear strain rate increased with increasing shear stress.

2. The results shown that the dynamic shear (stress, strain, strain rate) increased with add nano particles.

3. The results of the second group (composite with $2 \%$ nano carbon) shown good improvement in the shear properties of fiber glass/epoxy composite after added nano carbon, where the dynamic shear stress of composite increased by $24.91 \%$.

4. The results of the group (composite with $2 \%$ nano alumina) and shown best improvement in the shear properties of fiber glass/epoxy composite when added nano alumina, because the nano alumina composite have the best properties, where the dynamic shear stress of composite increased by $26.31 \%$

5. All group of materials affected by ( temperature and humidity ) and the fiber glass/epoxy composite was more effected than others where the shear stress and shear strain as shear stress decreased with increased temperature or humidity ,so the effect was greater with increased temperature and humidity together (hygrothermal effect) and the effect of the temperature was higher than the humidity.
6. Added nano particle increased the strength of composite under hygrothermal effect.

7. Used Johnson-Cook equation and modified to clarify the effect of the humidity by add new parameter $(\mathrm{k})$ and found the constants $\mathrm{A}, \mathrm{B}, \mathrm{C}$, $\mathrm{n}$,finally it can be used the modification on Johnson-Cook model with a reasonable percentage error.

8. It can be seen the reasonable percentage error between the results which obtained from Johnson-Cook constitutive model (theoretical method) 00 and experimental method.

\section{Acknowledgements}

I would like to thank allah for my success and I would like to express my deep grateful, thanks and respect to my supervisor Asst. Prof. Dr. Fadhel Abbas Abdullah for supervising this study and for her scientific guidance, moral support and patience. Last, I am grateful to my husband and my family, for the tremendous of inspiration and moral support they have given me through my whole life.

\section{REFERENCES}

[1] Robert K. Goldberg and Gary D. Roberts "Strain Rate Sensitivity of Epoxy Resin in Tensile and Shear Loading" Amos Gilat, Ohio State University, Columbus, Ohio, NASA/TM-2005-213595.

[2] S. P. Nawale1, R. T. Vyavahare2, A. S. Aradhye3 " A Review on Effect of High Strain Rate on Mechanical Behavior of Al based MMCs" International Journal of Emerging Technology and Advanced Engineering, Department of Mechanical Engineering ,India , July 2014.

[3] S. Sharma, V.M. Chavan, R.G. Agrawal and R.J. Patel S. Sharma, V.M. Chavan, R.G. Agrawal and R.J. Patel " AN EXPERIMENTAL TECHNIQUE FOR HIGH STRAIN RATE TESTS" Mechanical Metallurgy Division, MUMBAI, INDIA,2011.

[4] NASA John H. Glenn "Study of High Strain Rate Response of Composites" The Ohio State University RF Project No. 742677, 2003.

[5] Dr. Nabil Bassim "Torsional Hopkinson Testing" University of Manitoba, Department of Mechanical and Manufacturing Engineering, Winnipeg, Manitoba, Canada, June 2012.

[6] Ali Majid Ibraheem Al-Khazali "Investigation of Temperature Effect on Nanocomposite Materials Subjected to High Strain Rate Impact" Department of Mechanical Engineering, University of Al- Mustansiriyah, 2015.

[7] Identification no: 020302060020000001 Sikadur ${ }^{\circledR-52}$ Injection Type N "Sikadur 52" Email: mail@arconsupplies.co.uk, Web: www. arconsupplies.co.uk. 
[8] Waad Adnan Khalaf "Dynamic Behavior of Composite Materials Subjected to Torsional Stresses at High Strain Rate" Mechanical Engineering, College of Engineering of Al-Mustansiriyah University in 2017.

[9] Ala'a Jamal Mahdi "Environmental Effect on Thermal Insulation of Composite Materials" Mechanical Engineering Department, University of Al - Mustansiriya College of Engineering, 2014.

[10] Engin Kiranli,"Determination of Material Constitutive Equation of a Biomedical Grade Ti6Al4V Alloy for Cross-Wedge Rolling", A Thesis of Master Science, Engineering and Sciences in Material of Izmir Institute of Technology, September 2009.

[11] N.S. Brar, V.S. Joshi and B.W. Harris, "Constitutive Model Constants for Low Carbon Steels from Tension and Torsion
Data", AIP Conference Proceedings, Vol. (955), Issue (1), pp. 627-630 (2007)

[12] Gigi-Ionut NICOLaESCU, George-Amado STEFAN, Constantin ENACHE and Marius Valeriu CÂRMACI "Torsional Testing At High Strain Rates Using A KolsKy bar" Military Technical Academy, Bucharest, Romania, 2015.

[13] Niranjan K Naik, Kedar S Pandya, Venkateswara R Kavala, Wei Zhang and Nikhil A Koratkar " High-strain rate compressive behavior of multi-walled carbon nanotube dispersed thermoset epoxy resin" 1Aerospace Engineering Department, Indian Institute of Technology Bombay, Powai, Mumbai, India and Mechanical, Aerospace and Nuclear Engineering, Rensselaer Polytechnic Institute, Troy, NY, USA. 